\title{
Adsorption of $\mathrm{Ba}^{2+}$ ions at the hydroxyapatite/ $\mathrm{NaCl}$ solution interface
}

\author{
E. Skwarek ${ }^{1} \cdot$ W. Janusz ${ }^{1}$
}

Received: 11 October 2018 / Revised: 17 December 2018 / Accepted: 24 December 2018 / Published online: 4 January 2019 (c) The Author(s) 2019

\begin{abstract}
The study of the kinetics of barium adsorption at the hydroxyapatite/electrolyte interface using the radioactive isotope ${ }^{133} \mathrm{Ba}^{2+}$ was carried out. The course of adsorption kinetics indicates that at the beginning adsorption proceeds quickly and then slowly. Such adsorption kinetics is best described by the multiexpotential equation. The adsorption of $\mathrm{Ba}^{2+}$ ions at the hydroxyapatite/ electrolyte interface proceeds via their adsorption of ions on the surface groups with the release of proton and the exchange of $\mathrm{Ca}$ ions from the crystal lattice. The adsorption process has an insignificant effect on the crystal lattice parameters and crystallinity degree but due to the decrease of zeta potential leads to particles aggregation.
\end{abstract}

Keywords Hydroxyapatite $\cdot$ Kinetics of adsorption $\cdot$ Barium

\section{Introduction}

Hydroxyapatite based materials have found extensive applications in practice. Besides the studies of hydroxyapatite (HAp) usage as a biomaterial, there are numerous studies on hydroxyapatite as an adsorbent, catalyst, sensor, and in medicine: in drug delivery, medical imaging and tumour hypothermal treatment (Haider et al. 2017; Fihri et al. 2017). Substitution of calcium ions in the hydroxyapatite surface layer by the metal cations is the method used to develop new catalysts, sorbents, sensors and material of other applications (Wakamura et al. 1998; Zilm et al. 2016). To synthesize metal ions doped HAp nanoparticles, co-precipitation and ion adsorption and/or exchange methods are usually used (Wakamura et al. 1998). The former proceeds by introducing metal and calcium ions into the solution before precipitation of HAp while the latter takes place by adding the metal ion into the HAp suspension or the HAp powder into the cation solution. The precipitation method provides continuous distribution of metal ions from the bulk to surface layer while the ion exchange method usually results in higher

E. Skwarek

ewunias@hektor.umcs.lublin.pl

W. Janusz

wladyslaw.janusz@poczta.umcs.lublin.pl

1 Department of Radiochemistry and Colloid Chemistry, Maria Curie-Sklodowska University, Maria

Curie-Sklodowska Sq. 5, 20031 Lublin, Poland concentration of metal ions on the surface of HAp nanoparticles than in the bulk since ion-exchange is limited to the particles surface layer.

The substitution of barium ions in the hydroxyapatite lattice changes its properties and such materials were studied as catalysts (Sugiyama and Moffat 2002; Yasukawa et al. 1999; Moussa et al. 2017). Moreover, this process was considered to remove barium from water (Suzuki et al. 1981). It is commonly known that barium can replace calcium in bone and teeth (Boanini et al. 2010; Fischer et al. 2014). Most of the barium doped hydroxyapatite studies were carried on the samples prepared using the precipitation method and the adsorption of only barium ions was studied by Suzuki et al.(Suzuki et al. 1981). However, preparation of barium hydroxyapatite using the precipitation method forms the product that can contain carbonate ions in the solution of pH 12 (Yasukawa et al. 1999; Yodera et al. 2012). The alternative method of preparation of doped hydroxyapatite is adsorption or ion exchange. This method allows to prepare materials that sometimes have better properties than those prepared by the precipitation method (Li et al. 2017). Suzuki et al. prove that the adsorption affinity of $\mathrm{Ba}^{2+}$ ions from the solutions of 50 and $100 \mathrm{ppm}$ for hydroxyapatite is smaller than that for $\mathrm{Cd}^{2+}, \mathrm{Zn}^{2+}$ and $\mathrm{Ni}^{2+}$ ions (Suzuki et al. 1981).

The paper presents the results of studies on adsorption of $\mathrm{Ba}^{2+}$ ions kinetics and their adsorption as a $\mathrm{pH}$ function at the hydroxyapatite/ $\mathrm{NaCl}$ aqueous solution interface. The measurements of $\mathrm{Ba}^{2+}$ adsorption as a function of $\mathrm{pH}$ were made for the following initial concentrations of ions/ 
hydroxyapatite of $\mathrm{Ba}^{2+}$ ions: 0.000001, 0.00001, 0.0001 and $0.001 \mathrm{~mol} / \mathrm{dm}^{3}$. Additionally, the potentiometric titration of the suspension for determination of the effect of $\mathrm{Ba}^{2+}$ ions adsorption on the $\mathrm{H}^{+}$ions consumption/release from the surface as well as measurements of zeta potential using the electrophoresis method were conducted. The complementary XRD and particle size analyses of hydroxyapatite samples before and after adsorption of $\mathrm{Ba}^{2+}$ ions were performed.

\section{Experimental}

The sample hydroxyapatite (HAp) was purchased from Aldrich. Hydroxyapatite was washed with doubly distilled water until the constant conductivity about $0.5 \mu \mathrm{S} / \mathrm{cm}$ was achieved.

\subsection{Methods of measurements}

The specific surface area and porosity of the prepared samples of hydroxyapatite were determined from the nitrogen adsorption/desorption data. The nitrogen adsorption/desorption isotherms at $77 \mathrm{~K}$ were measured using the ASAP 2405 sorption analyzer (Accelerated Surface Area and Porosimetry) by the Micromeritics Instruments, Co. The specific surface area of the HAp sample calculated by the BET method was $100.6 \mathrm{~m}^{2} / \mathrm{g}$ and porosity calculated using the Barrett, Joyner and Halenda (BJH) procedure was $15.6 \mathrm{~nm}$.

The crystalline structure was determined using the $\mathrm{X}$-radiation diffraction. The PXRD radiation diffraction was studied by means of an X-ray diffractometer Empyrean produced by the PANalytical firm. The Rietveld refinement of the PXRD pattern of the samples was carried out using the Maud software (Ferrari and Lutterotti 1994). The PXRD analysis showed that the obtained sample possessed a crystalline structure of hydroxyapatite.

The adsorption of $\mathrm{Ba}^{2+}$ ions was determined by the static method with no repetitions using the radiotracer technique with radioisotope ${ }^{133} \mathrm{Ba}^{2+}$ as a radiotracer in the chemical $\mathrm{BaCl}_{2}$ form.

Measurements of $\mathrm{Ba}^{2+}$ ions adsorption were performed out in a thermostated Teflon vessel in nitrogen atmosphere at $25^{\circ} \mathrm{C}$. pH measurements were made using a PHM 240 Radiometer Research pHmeter with a G-201-8G glass electrode and REF-451 calomel reference electrode (with the double electrolyte junction). The titrant $(0.1 \mathrm{M} \mathrm{NaOH}$ solution) increments were added from an automatic burette, Metrohm 655 Dosimat. The whole procedure was controlled by a microcomputer. The computer program was designed so that titration was performed with the maximum drift of $\mathrm{pH}<0.002$ unit $\mathrm{pH} \mathrm{min}^{-1}$. The adsorption of $\mathrm{Ba}^{2+}$ ions proceeded was carried out from the $0.001 \mathrm{~mol} / \mathrm{dm}^{3} \mathrm{NaCl}$ solution as a background electrolyte. The initial $\mathrm{pH}$ of the solution of $0.001 \mathrm{M} \mathrm{NaCl}$ and the desired concentration of $\mathrm{BaCl}_{2}$ were fixed by the addition of $\mathrm{HCl}$. Next $50 \mathrm{ml}$ of the solution was labelld with the ${ }^{133} \mathrm{Ba}^{2+}$ radioisotope (from Polatom, Poland). The $0.5 \mathrm{~g}$ Hydroxyapatite sample was subsequently added to the solution. During the potentiometric titration, $0.5 \mathrm{ml}$ of the suspension sample was collected after each equilibrium $\mathrm{pH}$ and centrifuged in a high-speed centrifuge to remove all solid particles. The $0.1 \mathrm{ml}$ of supernatant was placed on the piece of filter paper to prepare the radiosources for scintillation counting. The reference radiosources were also prepared with the initial labeld salt solutions. The radioactivity of electrolyte solution before and after adsorption was measured using the automatic gamma counter by Perkin Elmer. Based on the radioactivity changes before and after adsorption sorption of $\mathrm{Ba}^{2+}$ ions on the surface of hydroxyapatite was calculated from the equations:

$c_{r}=c_{0} \frac{N_{r}-N_{t}}{N_{0}-N_{t}}$

and

$A=\frac{V}{m s_{w}}\left(c_{0}-c_{r}\right)$

where:

$\mathrm{c}_{0}$ - the initial concentration $\left[\mathrm{mol} / \mathrm{dm}^{3}\right]$

$\mathrm{V}$ - the volume of solution sample $\left[\mathrm{dm}^{3}\right]$

$\mathrm{M}$ - the hydroxyapatite sample weight $[\mathrm{g}]$

$\mathrm{S}_{\mathrm{w}}$-the specific surface area $\left[\mathrm{m}^{2} / \mathrm{g}\right]$

$\mathrm{N}_{\mathrm{r}}$ - the number of countings from the source during adsorption,

$\mathrm{N}_{0}$ - the number of countings from the source from the solution before adsorption,

$\mathrm{N}_{\mathrm{t}}$-the number of countings from the background radiation,

$\mathrm{c}_{\mathrm{r}}$ - the equilibrium concentration $\left[\mathrm{mol} / \mathrm{dm}^{3}\right]$,

$\mathrm{A}=$ adsorption $\left[\mathrm{mol} / \mathrm{m}^{2}\right]$.

The zeta potential was measured by the electrophoretic method using Zetasizer Nano-ZS, Malvern. In the zeta potential calculations the Smoluchowsky's equation was also applied because of $\kappa a \sim 150$. Particle size distribution was determined using Mastersizer 2000 produced by the Mavern firm.

\section{Results and discussion}

According to the literature reports uptake of metal ions in the hydroxyapatite suspensions is considered as the results of the following processes:

- exchange of metal ions with $\mathrm{Ca}$ ions in the crystal lattice of hydroxyapatite (Sugiyama et al. 1999). P.Z. Saleb 
and P.L. de Bruyn formulated two conditions for cation to be exchanged: the radius of the exchanged cation should not differ from that of $\mathrm{Ca}^{2+}$ more than $15 \%$ and the electronegativity of cation should be high (Saleb and Bruyn 1972). Suzuki et al. determined the range radius of the exchanged ions from 0.09 to $0.13 \mathrm{~nm}$ (Suzuki et al. 1982). However, Reinchert et al. stated that the ions that have the radius above this limit can exchange calcium in the HAp lattice (Reichert and Binner 1996). $\mathrm{Ba}^{2+}$ ions have a radius of $0.149 \mathrm{~nm}$ and it differs significantly from that of $\mathrm{Ca}^{2+}$ ions. The exchange of ions does not take place only on the surface of hydroxyapatite but also in the natural channels $\mathrm{CaII}$ and $\mathrm{CaI}$ in the hydroxyapatite lattice (Monteil Riveira and Fedoroff 2004).

- adsorption of metal ions on the surface group (phosphate or hydroxyl) with release of one or two protons as a result of adsorption on one or two surface groups, respectively (Sheha 2007),

- subsequent dissolution of hydroxyapatite and precipitation of new metal phosphate phase (Hashimoto and Sato 2007). This process occurs at the high initial concentration of divalent metal cation $>0.001 \mathrm{~mol} / \mathrm{dm}^{3}$ and acid $\mathrm{pH}$ of solution (Smicklas 2003).
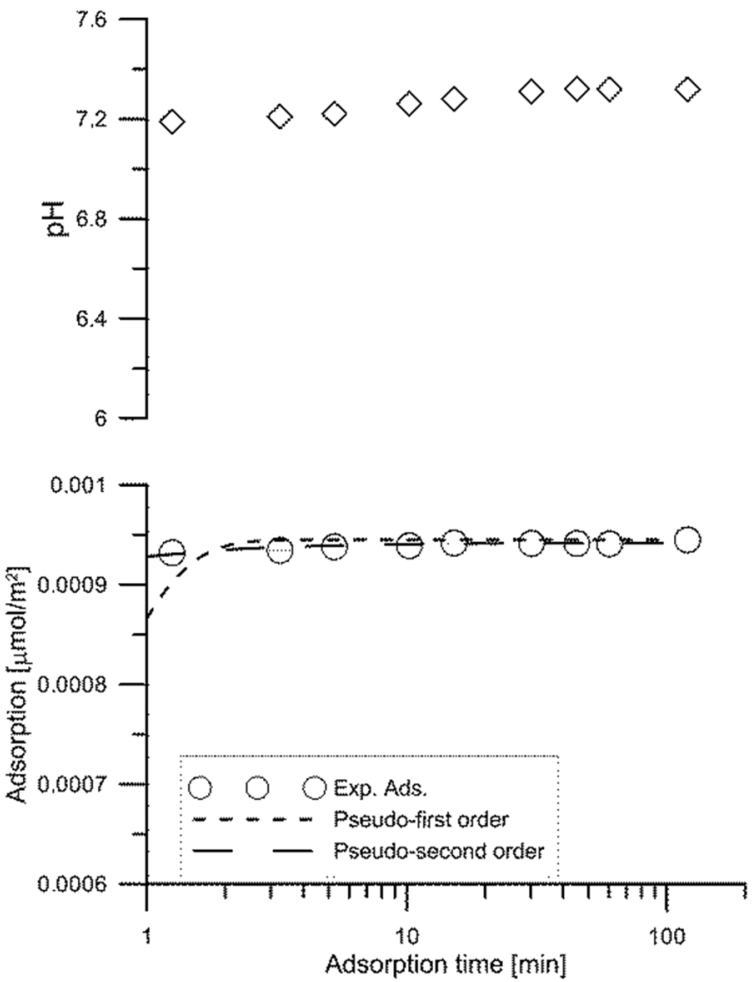

Fig. 1 Kinetics of $\mathrm{pH}$ and $\mathrm{Ba}^{2+}$ ions adsorption/desorption changes on hydroxyapatite from the $\mathrm{Ba}^{2+}$ ions solution of the initial concentration $0.000001 \mathrm{~mol} / \mathrm{dm}^{3}$. The points indicate the experimental data, for the selected system two of them can occur simultaneously (Wakamura et al. 1998; Xu et al. 1994).

\subsection{Kinetics of barium ions adsorption at the hydroxyapatite/electrolyte interface}

The kinetics of $\mathrm{Ba}^{2+}$ ions adsorption at the hydroxyapatite $/ 0.001 \mathrm{~mol} / \mathrm{dm}^{3} \mathrm{NaCl} \mathrm{mol} / \mathrm{dm}^{3}$ aqueous solution interface from the solution of the initial concentration of 0.001 and $0.000001 \mathrm{~mol} / \mathrm{dm}^{3}$ is depicted in Figs. 1 and 2, respectively. As can be seen in Fig. 1 adsorption of $\mathrm{Ba}^{2+}$ ions from the solution of the initial concentration $0.000001 \mathrm{~mol} / \mathrm{dm}^{3}$ proceeds quickly, during the first minute adsorption achieves the maximum value. According to the literature several models can be used to describe kinetics of ions adsorption (Marczewski. 2007). However the kinetic cation adsorption at hydroxyapatite was efficiently express by: the pseudofirst order equation or by means of the pseudo-second order equation, particle intraparticle diffusion model and multiexponential equation. These models were used for description of kinetics of $\mathrm{Ba}^{2+}$ adsorption at hydroxyapatite. At this low initial concentration $0.000001 \mathrm{~mol} / \mathrm{dm}^{3} \mathrm{Ba}^{2+}$, the difference of fitting is small, however, the fitting made using the mulitexponential or pseudo-second order model describes adsorption kinetics better than the other equations. Figure 1

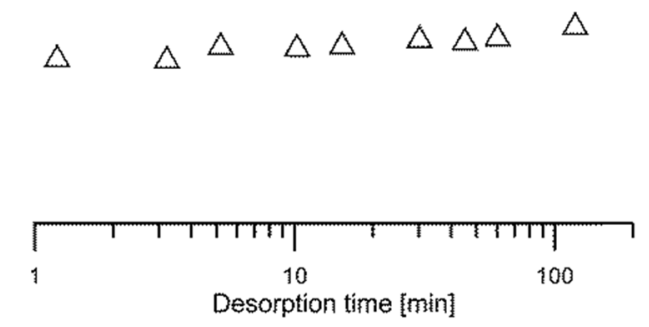

the broken line-the pseudo-first order model for $\mathrm{q}_{\mathrm{e}}=0.00094$ and $\mathrm{k}_{1}=2.482$, the broken line of longer segments- the pseudo-second order model for $\mathrm{q}_{\mathrm{e}}=0.00094$ and $\mathrm{k}_{2}=7.1368$ 


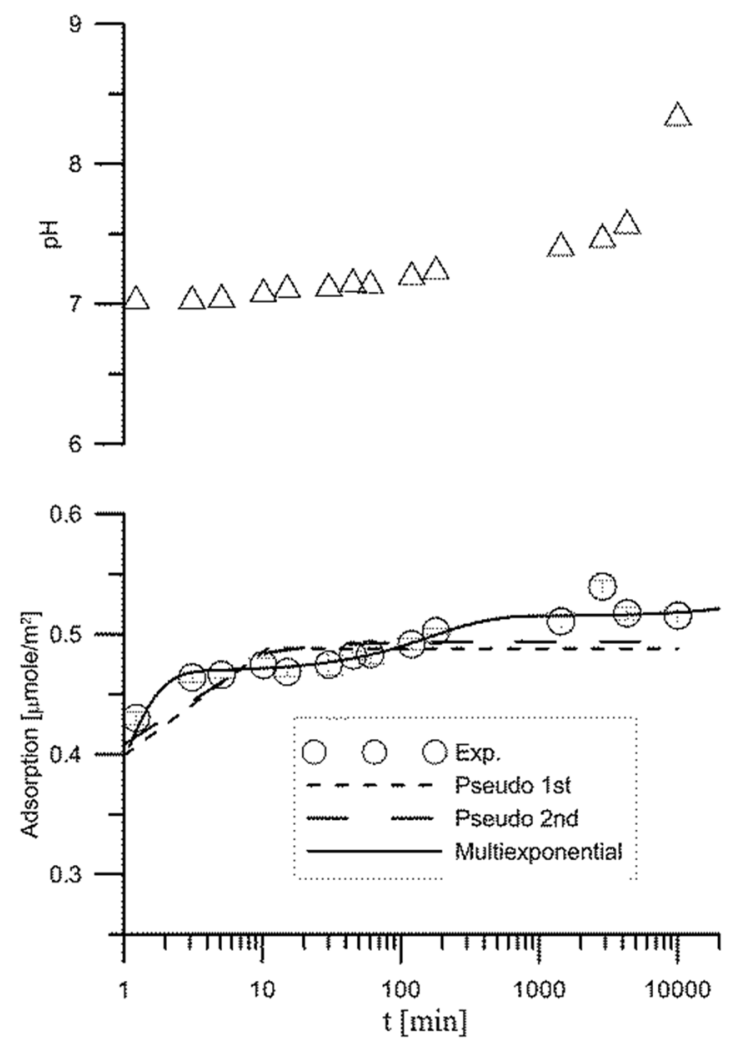

Fig. 2 Kinetics of $\mathrm{pH}$ and $\mathrm{Ba}^{2+}$ ions adsorption/desorption changes on hydroxyapatite from the $\mathrm{Ba}^{2+}$ ions solution of the initial concentration $0.001 \mathrm{~mol} / \mathrm{dm}^{3}$. The points indicate the experimental data, the broken line-the pseudo-first order model for $\mathrm{q}_{\mathrm{e}}=0.488$ and $\mathrm{k}_{1}=1.702$,

shows also the kinetics of $\mathrm{Ba}^{2+}$ ions desorption as a result of $\mathrm{pH}$ decrease to 6.17 (this causes competition of $\mathrm{H}^{+}$or $\mathrm{Ca}^{2+}$ ions released from solubility of hydroxyapatite with the adsorbed $\mathrm{Ba}^{2+}$ ion), as can be seen at the beginning of desorption $\sim 18 \%$ of adsorbed $\mathrm{Ba}^{2+}$ ions was released into the solution but after the 120 min desorption, the $\mathrm{pH}$ of the suspension increases to 6.35 and results in the increase of $\sim 3 \%$ adsorption of $\mathrm{Ba}^{2+}$ ions. That provides strong adsorption affinity of $\mathrm{Ba}^{2+}$ ions for the hydroxyapatite surface.

The kinetics of adsorption/desorption of $\mathrm{Ba}^{2+}$ ions from the solution of the initial concentration $0.001 \mathrm{~mol} / \mathrm{dm}^{3}$ and changes of $\mathrm{pH}$ in the hydroxyapatite/aqueous solution of $0.001 \mathrm{~mol} / \mathrm{dm}^{3} \mathrm{NaCl}$ are depicted in Fig. 2. As one can see the adsorption proceeds via three steps: the first one fast, the second and third ones slow. This course of adsorption and the time of achieving equilibrium differ from that of the other divalent ions e.g. $\mathrm{Sr}^{2+}, \mathrm{Cd}^{2+}, \mathrm{Co}^{2+}$ where their adsorption on hydroxyapatite proceeds via two steps; the first one fast and the second slow(Janusz and Skwarek 2016; Skwarek and Janusz 2016; Smiciklas et al. 2006). Different adsorption kinetics of $\mathrm{Ba}^{2+}$ ions may be due to the ionic radius of $\mathrm{Ba}^{2+}$ ions that fall outside the limit of cation radius which results the exchange in the crystal structure will not deform

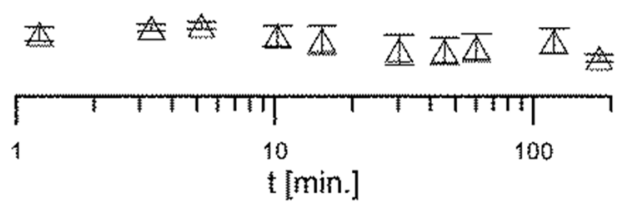

the broken line of longer segments- the pseudo-second order model for $\mathrm{q}_{\mathrm{e}}=0.495$ and $\mathrm{k}_{2}=9,64$. The continuous line-multiexponential model: $\mathrm{a}_{\mathrm{eq}}=3.637, \mathrm{~A}_{0}=0.0043, \mathrm{k}_{1}=1.831, \mathrm{~A}_{1}=0.128, \mathrm{k}_{2}=1 \times 10^{-7}$, $\mathrm{A}_{2}=0.854, \mathrm{k}_{2}=0.0061, \mathrm{~A}_{2}=0.0126$

it significantly (Reichert and Binner 1996). The larger radius of $\mathrm{Ba}^{2+}$ cations in comparison to $\mathrm{Ca}^{2+}$ limits the diffusion of $\mathrm{Ba}^{2+}$ ions in the crystal lattice channel of hydroxyapatite so the slow step of $\mathrm{Ba}^{2+}$ ions adsorption is delayed. As it can be seen in Fig. 2, the kinetics of adsorption was the best expressed by the multiexponential model with three exponential terms that reflect the porous structure of hydroxyapatite (Marczewski. 2007) or uptake of $\mathrm{Ba}^{2+}$ ion by the dissolution/precipitation process. However, comparing the decrease of $\mathrm{Ba}^{2+}$ concentration from 30 min of adsorption to $10080 \mathrm{~min}$ and the increase of $\mathrm{OH}^{-}$concentration, it follows that barium hydroxyapatite could not be formed as a result of precipitation because the increase of concentration of $\mathrm{OH}^{-}$ions was observed. The additional effect of adsorption increase after $30 \mathrm{~min}$ may be due to the dispersion of hydroxyapatite aggregates in the suspension and exposition of hydroxyapatite surface that was not accessible to $\mathrm{Ba}^{2+}$ ions adsorption before. In Fig. 2. desorption of $\mathrm{Ba}^{2+}$ ions as an effect of $\mathrm{pH}$ decrease to 5.88 was equal to $\sim 41 \%$ and, in comparison with that depicted in Fig. 1 suggests that in this case more $\mathrm{Ba}^{2+}$ adsorbed ions are weakly bound to the hydroxyapatite surface. The adsorption density of $\mathrm{Ba}^{2+}$ ions during the desorption process for over $100 \mathrm{~min}$ does not 
change significantly although $\mathrm{pH}$ increases because of the hydroxyapatite solubility.

\subsection{Adsorption of $\mathrm{Ba}^{2+}$ ions as a function of $\mathrm{pH}$}

As mentioned above the adsorption of $\mathrm{Ba}^{2+}$ ions on hydroxyapatite proceeds via three pathways: ion exchange with calcium ions of crystal lattice, reaction with the surface groups (hydroxyl or hydrogen phosphate, $\equiv \mathrm{SOH}$ ) and dissolution of hydroxyapatite/precipitation of new phase. The dependence of cation adsorption as a function of $\mathrm{pH}$ is observed for the reaction of cation from the surface group where release of proton takes place e.g.:

$\equiv \mathrm{SOH}+\mathrm{Ba}^{2+} \rightleftarrows \equiv \mathrm{SO}^{-} \mathrm{Ba}^{2+}+\mathrm{H}^{+}$

$2 \equiv \mathrm{SOH}+\mathrm{Ba}^{2+} \rightleftarrows \equiv\left(\mathrm{SO}^{-}\right)_{2} \mathrm{Ba}^{2+}+2 \mathrm{H}^{+}$

where: $\equiv \mathrm{SOH}$ denotes the surface groups e.g hydrogen phosphate or hydroxyl groups,

As one can see reaction one leads to release of one proton per adsorbed one divalent cation whereas reaction two leads to release of two protons. Adsorption in reaction one at a higher concentration may lead to overcharging of the compact part of the electrical double layer. The ion exchange mechanism of adsorption of divalent cations leads to release of calcium ions into solution, change of calcium concentration will influence on cation adsorption. However, calcium concentration in the hydroxyapatite suspensions depends also on $\mathrm{pH}$ because of its solubility, so finally adsorption of cations via this mechanism will be also $\mathrm{pH}$ dependent. As the concentration of calcium and phosphate ions due to dissolution of hydroxyapatite changes with $\mathrm{pH}$, the mechanism of divalent ions uptake as a result of dissolution/precipitation will change with $\mathrm{pH}$.

The adsorption density and concentration of $\mathrm{Ba}^{2+}$ ions as a function of $\mathrm{pH}$ are presented in Figs. 3 and 4 for the initial concentrations 0.0000001 and $0.001 \mathrm{~mol} / \mathrm{dm}^{3}$ of $\mathrm{Ba}^{2+}$ ions, respectively. As be for the initial concentrations 0.00001 , adsorption of $\mathrm{Ba}^{2+}$ ions in the $\mathrm{pH}$ function increases in the $\mathrm{pH}$ range from 7 to 9 and then almost the whole amount of $\mathrm{Ba}^{2+}$ ions is adsorbed (concentration of $\mathrm{Ba}^{2+}$ ions in the solution decreases to $10^{-10} \mathrm{~mol} / \mathrm{dm}^{3}$ ), Fig. 4 . For the initial concentration of $0.001 \mathrm{~mol} / \mathrm{dm}^{3}$ of $\mathrm{Ba}^{2+}$ ions in the studied range of $\mathrm{pH}$ the increase of $\mathrm{Ba}^{2+}$ ions adsorption with the $\mathrm{pH}$ increase was observed (Fig. 2). At $\mathrm{pH}=748 \%$ of $\mathrm{Ba}^{2+}$ ions but at $\mathrm{pH} 1095 \%$ of $\mathrm{Ba}^{2+}$ ions were adsorbed.

The sorption of $\mathrm{Ba}^{2+}$ ions at the hydroxyapatite $/ 0.001 \mathrm{~mol} / \mathrm{dm}^{3} \mathrm{NaCl}$ solution interface as a function of $\mathrm{Ba}^{2+}$ ions concentration is presented in Fig. 5. The points show the experimental sorption data for the three values of $\mathrm{pH} 7.5,9$ and 10.5. As one can see to the sorption isotherm course of $\mathrm{Ba}^{2+}$ ions above the initial concentration $0.001 \mathrm{~mol} / \mathrm{dm}^{3}$ indicates bulk precipitation of new phase e.g.

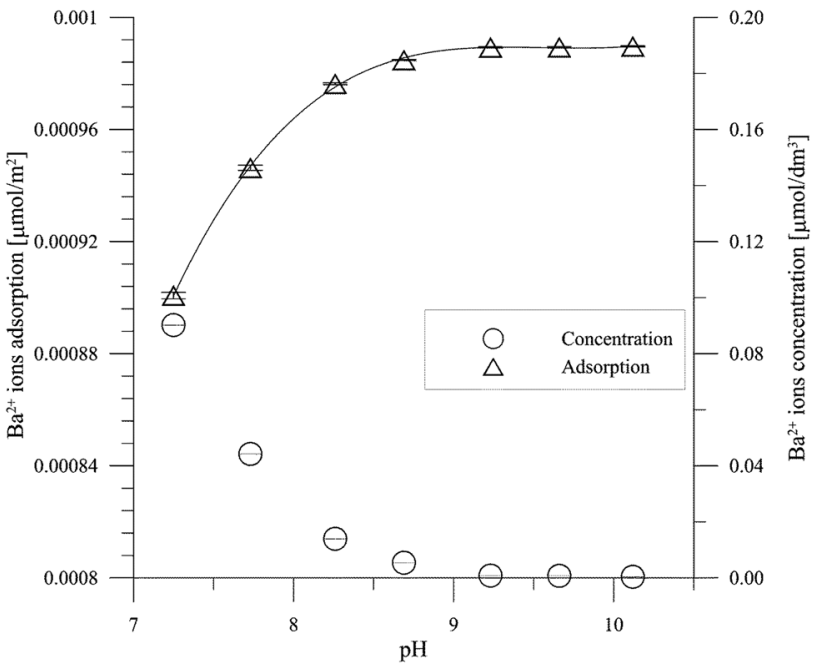

Fig. 3 Dependence of adsorption density and concentration of $\mathrm{Ba}^{2+}$ on $\mathrm{pH}$ for the hydroxyapatite $/ 0.001 \mathrm{~mol} / \mathrm{dm}^{3} \mathrm{NaCl}+0.000001 \mathrm{~mol} /$ $\mathrm{dm}^{3} \mathrm{Ba}^{2+}$

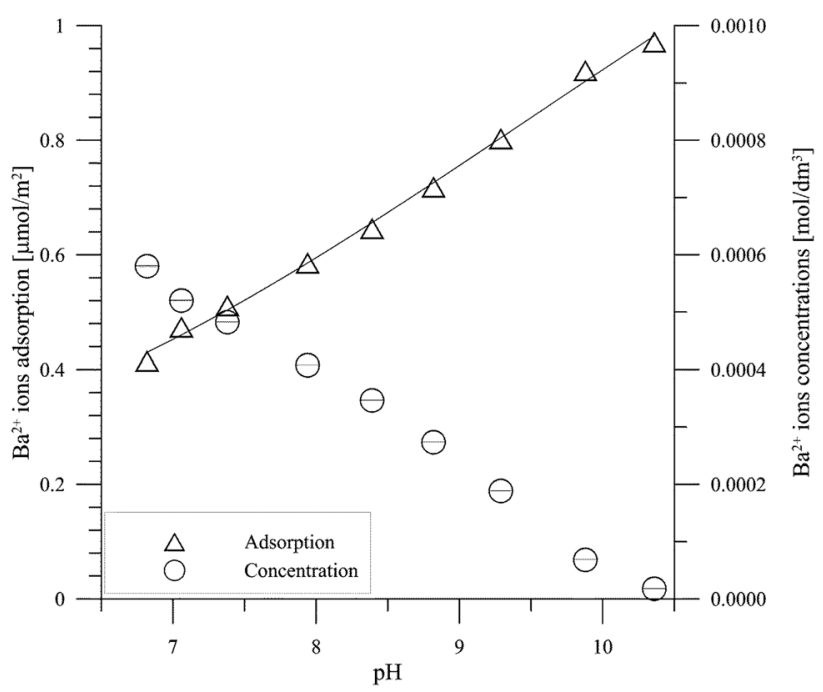

Fig. 4 Dependence of adsorption density and concentration of $\mathrm{Ba}^{2+}$ on $\mathrm{pH}$ for the hydroxyapatite $/ 0.001 \mathrm{~mol} / \mathrm{dm}^{3} \mathrm{NaCl}+0.001 \mathrm{~mol} / \mathrm{dm}^{3}$ $\mathrm{Ba}^{2+}$

barium phosphate (Hayes and Katz 2000). The lines in Fig. 5 indicate the Langmuir isotherms fit in the range of initial concentration of $\mathrm{Ba}^{2+}$ ions from 0.000001 to $0.001 \mathrm{~mol} / \mathrm{dm}^{3}$, the parameters are summarized in Table 1 . The coverage with a monolayer at these $\mathrm{pH}$ values, calculated from the Langmuir isotherm was $0.362,0.440$ and $0.629 \mu \mathrm{mol} / \mathrm{m}^{2}$, respectively. In the range of low concentrations, the adsorption $\log$ vs. the concentration log has a linear course and the direction coefficient indicates that the adsorption proceeds on the surfaces of energetically heterogeneous adsorption sites (Stumm 1992). According to Kukura et al. the 


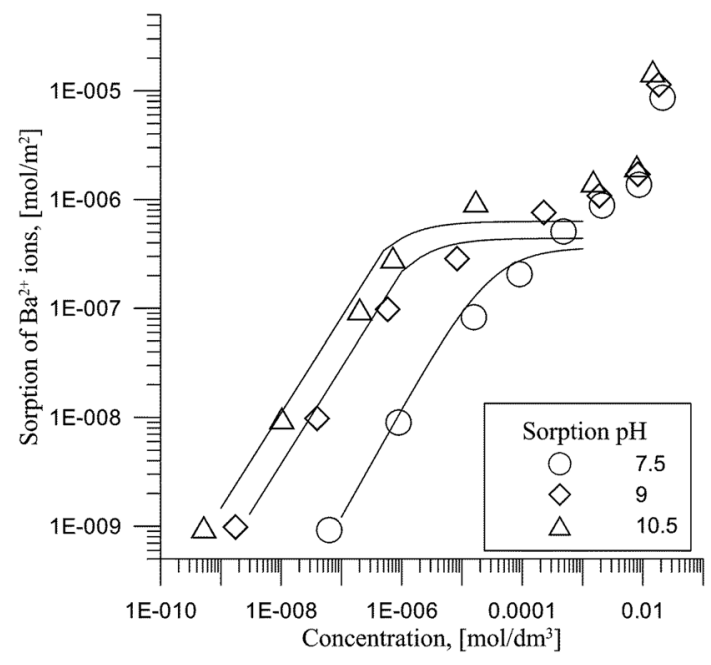

Fig. 5 Barium ions sorption in the hydroxyapatite/0.001 $\mathrm{mol} / \mathrm{dm}^{3}$ $\mathrm{NaCl}$ electrolyte system as a function of concentration

Table 1 The maximum adsorption capacity $\mathrm{q}_{\mathrm{m}}$, Langmuir constants$\mathrm{K}_{\mathrm{L}}$, and correlation factor $\mathrm{R}$ calculated from the Langmuir equation

\begin{tabular}{llrl}
\hline $\mathrm{pH}$ & $\mathrm{q}_{\mathrm{m}}\left[\mu \mathrm{mol} / \mathrm{m}^{2}\right]$ & $\mathrm{K}_{\mathrm{L}}\left[\mathrm{dm}^{3} / \mathrm{mol}\right]$ & $\mathrm{R}$ \\
\hline 7.5 & 0.362 & 33668.3 & 0.800 \\
9.0 & 0.440 & 983926.1 & 0.715 \\
10.5 & 0.629 & 2329183.6 & 0.725 \\
\hline
\end{tabular}

concentration of $\mathrm{Ca}^{2+}$ and $\mathrm{PO}_{4}{ }^{3-}$ lattice ions on hydroxyapatite was equal to 4.5 and 3.2 ions $/ \mathrm{nm}^{2}$, respectively (Kukura et al. 1972). The concentration of $-\mathrm{OH}$ group, calculated on the basis of crystallographic data, was 2.5 group $/ \mathrm{nm}^{2}$, however, determined from the IR spectra it was $1 \pm 0.4$ groups/ $\mathrm{nm}^{2}$. (Kukura et al. 1972; Bertinetti et al. 2007). The comparison of the monolayer values from the Langmuir isotherm with the concentration of surface $\mathrm{OH}$ groups, and $\mathrm{Ca}^{2+}$ and $\mathrm{PO}_{4}{ }^{3-}$ lattice ions shows that only part of accessible sites was occupied. This may be a result of greater ionic radius of $\mathrm{Ba}^{2+}$ ions in comparison to $\mathrm{Ca}^{2+}$ ions that restricts the ion exchange process.

The effect of $\mathrm{Ba}^{2+}$ ions adsorption on the dependence of hydrogen ions consumption/release is presented in Fig. 6 . As can be seen barium ions adsorption from the solutions of the initial concentration smaller or equal to $0.0001 \mathrm{~mol} / \mathrm{dm}^{3}$ does not cause significant changes in consumption/ release of hydrogen ions. However, barium ions adsorption from the solution of the barium initial concentration $0.001 \mathrm{~mol} /$ $\mathrm{dm}^{3}$ results in the significant $\mathrm{H}^{+}$ions release. This effect is connected with the reactions of barium ions with the surface hydroxyl groups or the hydrophosphate groups with proton release.

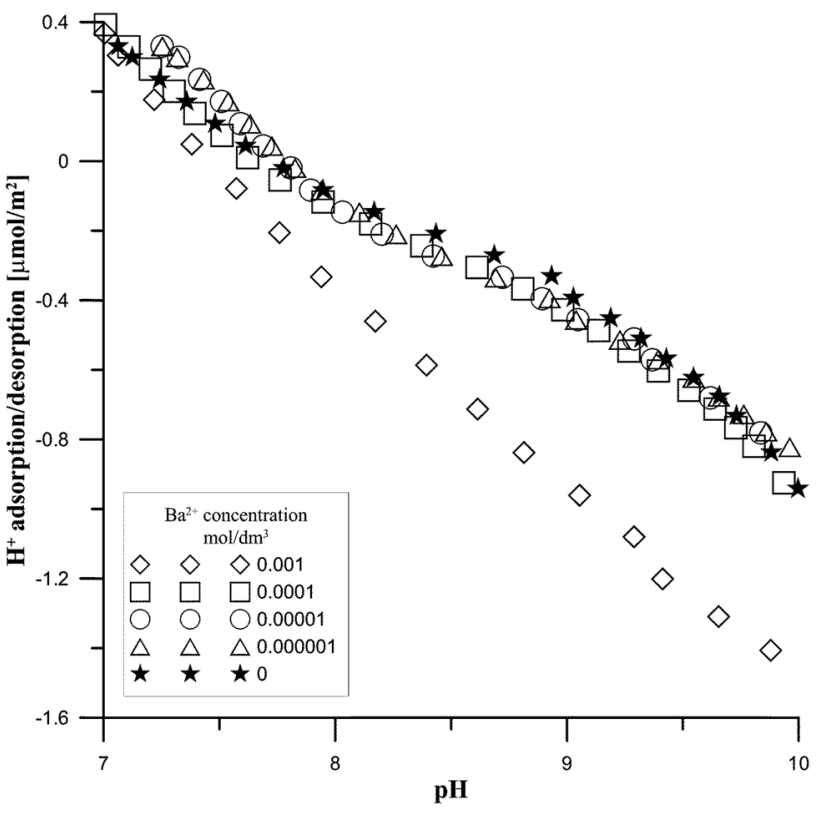

Fig. 6 Effect of $\mathrm{Ba}^{2+}$ ions adsorption on the uptake of $\mathrm{H}+$ ions in the $\mathrm{HAp} / 0.001 \mathrm{~mol} / \mathrm{dm}^{3} \mathrm{NaCl}+\mathrm{mol} / \mathrm{dm}^{3} \mathrm{Ba}^{2+}$ system

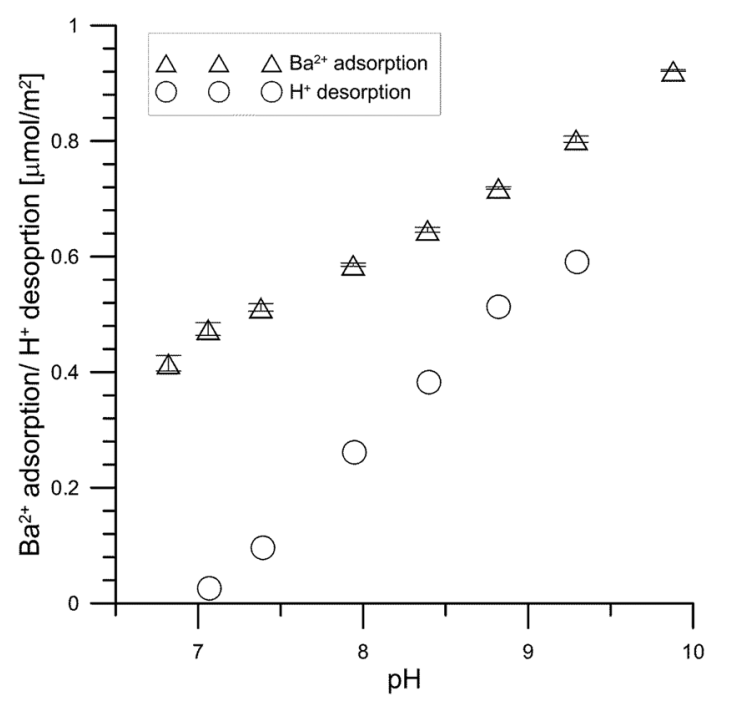

Fig. 7 The comparison of the adsorbed $\mathrm{Ba}^{2+}$ ions with the desorbed $\mathrm{H}^{+}$ions in the $\mathrm{HAp} / 0.001 \mathrm{~mol} / \mathrm{dm}^{3} \mathrm{NaCl}+0.001 \mathrm{~mol} / \mathrm{dm}^{3} \mathrm{Ba}^{2+}$ system

The comparison of $\mathrm{Ba}^{2+}$ ions adsorption from the solution of the initial concentration $0.001 \mathrm{~mol} / \mathrm{dm}^{3}$ of the $\mathrm{Ba}^{2+}$ ions with the $\mathrm{H}^{+}$ions desorption is presented in Fig. 7. As can be seen from Fig. 7 at $\mathrm{pH} 7$ the adsorption of $\mathrm{Ba}^{2+}$ ions is equal to $0.47 \mu \mathrm{mol} / \mathrm{m}^{2}$ and the desorption of $\mathrm{H}^{+}$ions is $0.026 \mu \mathrm{mol} / \mathrm{m}^{2}$ which shows that the adsorption results mainly from ion exchange. Increase of $\mathrm{pH}$ leads to higher contribution of $\mathrm{Ba}^{2+}$ ions adsorption on the surface hydroxyl 
groups over ions exchange, and this process at $\mathrm{pH} 10$ gives more than $80 \%$ contribution.

Figure 8 presents the effect of $\mathrm{Ba}^{2+}$ ions adsorption from the solution of the initial concentration of $0.00001,0.0001$ and $0.001 \mathrm{~mol} / \mathrm{dm}^{3}$ on the zeta potential as a function of $\mathrm{pH}$. As can be seen the specific adsorption of $\mathrm{Ba}^{2+}$ ions leads to the decrease of absolute value of negative zeta potential as a result of adsorption of each divalent $\mathrm{Ba}^{2+}$ ion on one surface group not only to compensate the negative charge but also to bring the additional positive charge into the compact part of electrical double layer.

\subsection{PXRD study of the $\mathrm{Ba}^{2+}$ ion adsorption of ion on hydroxyapatite}

Substitution of $\mathrm{Ca}^{2+}$ ions in the hydroxyapatite lattice by those of smaller size in the crystal bulk (by the precipitation method) leads to a significant decrease of lattice constants. They are increased due to substitution by large ions. The effect of adsorption of divalent ion onto hydroxyapatite on its crystal structure at low concentration of metal ions in the HAp/electrolyte solution system changes slightly and depends on the size of adsorbed ion. However, for the same systems it was reported that in the XRD pattern some peaks of a new phase were observed. The opinions reported in two different papers are presented. Smiciklas and co-workers stated that adsorption of $\mathrm{Co}^{2+}$ ions results in a slight decrease in the unit cell parameters whereas Pan and co-workers found a reflection characteristic of cobalt hydroxyapatite(Smiciklas et al. 2006; Pan et al. 2009). The structure of the hydroxyapatite samples conditioned for 2 weeks: one in the solution of $0.001 \mathrm{~mol} / \mathrm{dm}^{3} \mathrm{NaCl}$ and the other one in the mixture of $0.001 \mathrm{~mol} / \mathrm{dm}^{3} \mathrm{NaCl}$ and

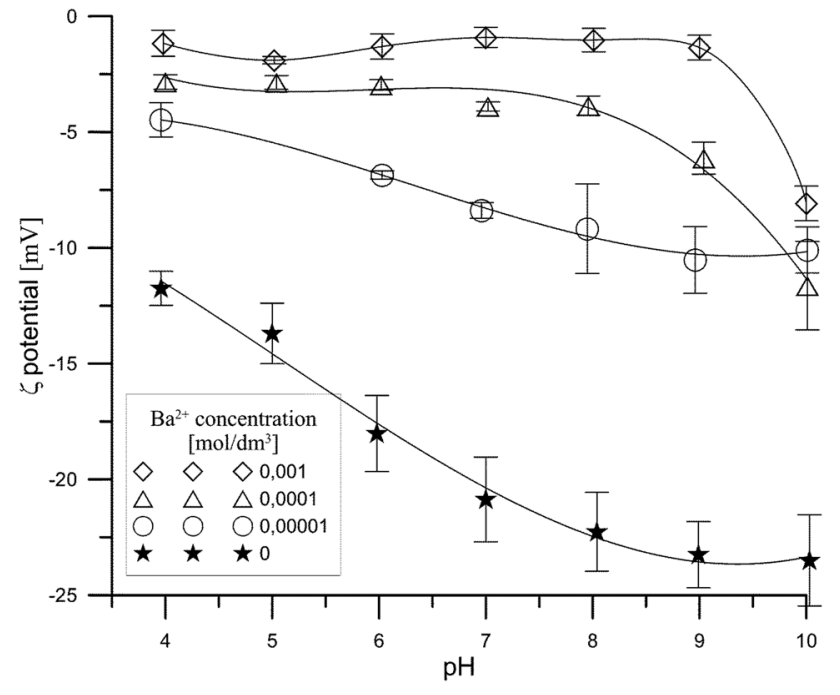

Fig. 8 The effect of $\mathrm{Ba}^{2+}$ ions concentration on the zeta potential of hydroxyapatite as a function of $\mathrm{pH}$
$0.001 \mathrm{~mol} / \mathrm{dm}^{3} \mathrm{Ba}^{2+}$ ions after separation from solution and drying was examined using the PXRD method. Next the PXRD pattern was refined by means of the Rietveld method using the Maud software (Ferrari and Lutterotti 1994). As the initial models for the refinement the cif file was used (Sudarsanan and Young 1969). The XRD pattern of the sample HAp with the adsorbed $\mathrm{Ba}^{2+}$ ions and the Rietveld refinement plot are depicted in Fig. 9. The calculated lattice constants using the Maud software are collected in Table 2. As you can see in Fig. 9 the Rietveld refinement of PXRD pattern of hydroxyapatite substituted by the adsorption hydroxyapatite $\mathrm{Ba}^{2+}$ ions does not reveal changes in the hydroxyapatite. The structure reflection from the PDF card 64-738 fits the experimental PXRD reflection, and the fitting parameters (sig and Rwp) are pretty good.

The substitution of divalent metal ions in the hydroxyapatite lattice can change not only the crystal lattice constants but also the crystal size and crystallinity degree. The crystallinity degree was calculated using the Landi et al. equation and taking into account the intensity of (300) reflection and the value of hollow between (112) and (300) reflections

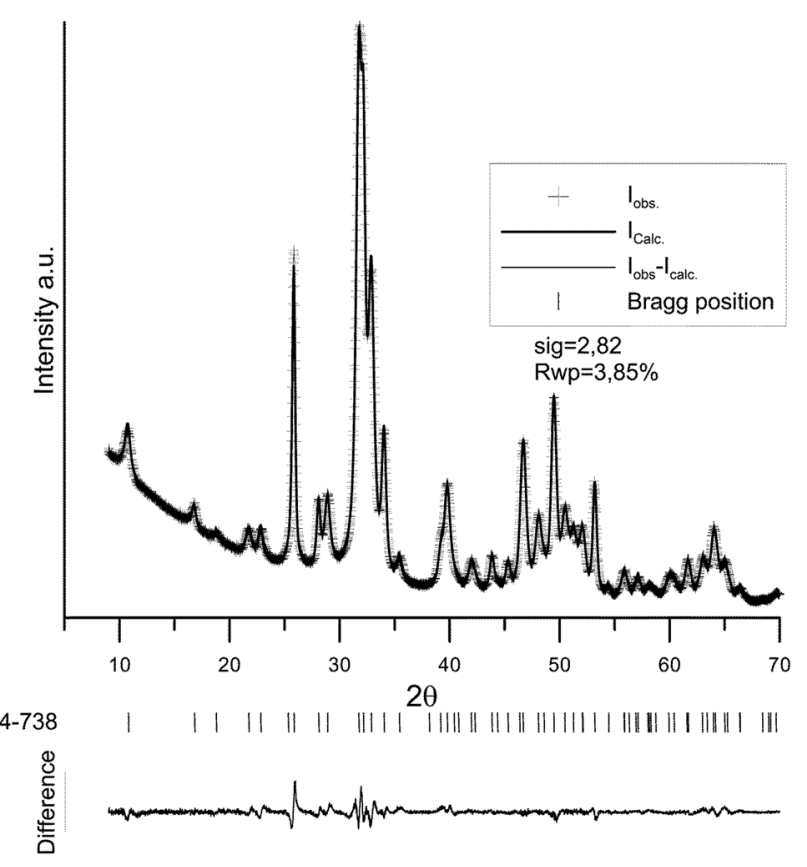

Fig. 9 The PXRD pattern of hydroxyapatite with the adsorbed $\mathrm{Ba}^{2+}$ ions after 2 weeks of conditioning in the solution of the initial concentration $0.001 \mathrm{~mol} / \mathrm{dm}^{3}$ of $\mathrm{Ba}^{2+}$ ions

Table 2 The hydroxyapatite lattice constants

\begin{tabular}{llllll}
\hline Sample & $\mathrm{a}[\AA]$ & $\mathrm{c}[\AA]$ & $\mathrm{V}\left[\AA^{3}\right]$ & Sig & Rwp [\%] \\
\hline $\mathrm{HAp}$ & $9.4262(2)$ & $6.8856(1)$ & 529.84 & 3.93 & 6.50 \\
$\mathrm{HAp} / \mathrm{Ba}^{2+}$ & $9.4225(2)$ & $6.8825(1)$ & 529.19 & 2.82 & 3.85 \\
\hline
\end{tabular}


Table 3 The crystal size and crystallinity degree of the HAp samples matured for 2 weeks in the aqueous solutions

\begin{tabular}{lllllc}
\hline Solution & $\mathrm{D}(002)[\mathrm{nm}]$ & $\mathrm{D}(300)[\mathrm{nm}]$ & $\mathrm{D}(002) / \mathrm{D}(300)$ & $\mathrm{V}[\mathrm{nm} 3]$ & $\begin{array}{c}\text { Crystallity } \\
\text { degree [\%] }\end{array}$ \\
\hline- & $28.7 \pm 0.3$ & $14.7 \pm 0.5$ & 1.96 & 15990.8 & 21.64 \\
$\mathrm{NaCl}$ & $28.9 \pm 0.1$ & $17.0 \pm 0.1$ & 1.70 & 21736.2 & 20.07 \\
$\mathrm{NaCl}+\mathrm{Ba}^{2+}$ & $29.6 \pm 0.1$ & $15.5 \pm 0.3$ & 1.91 & 18423.4 & 20.00 \\
\hline
\end{tabular}

Table 4 Structural porosity parameters and specific surface area of the hydroxyapatite samples

\begin{tabular}{llll}
\hline & Solution & & \\
\cline { 2 - 4 } & - & $0.001 \mathrm{~mol} / \mathrm{dm}^{3} \mathrm{NaCl}$ & $\begin{array}{c}0.001 \mathrm{~mol} / \mathrm{dm}^{3} \\
\mathrm{NaCl}+0.001 \mathrm{~mol} / \\
\mathrm{dm}^{3} \mathrm{Ba}^{2+}\end{array}$ \\
\hline BET surface area $\left[\mathrm{m}^{2} / \mathrm{g}\right]$ & & $105.57 \pm 2.15$ & $106.22 \pm 2.15$ \\
BJH adsorption cumulative volume of pores between 1.7 and & 0.46 & 0.46 & 0.47 \\
300 nm diameter $\left[\mathrm{cm}^{3} / \mathrm{g}\right]$ & $100.64 \pm 2.15$ & 14.99 & 15.46 \\
BJH desorption on average pore diameter (4V/A) [nm] & 15.51 & 18.83 & 18.93 \\
Diameter of pore size distribution peak & 18.52 & \\
\hline
\end{tabular}

(Landi et al. 2000). The values of the crystal size were calculated using the Scherrer equation from FWHM of (002) and (300) reflections (Smiciklas et al. 2008). The crystal size and crystallinity degree are collected in Table 3 for the initial sample and that matured in the $0.001 \mathrm{~mol} / \mathrm{dm}^{3} \mathrm{NaCl}$ aqueous solution and the $0.001 \mathrm{~mol} / \mathrm{dm}^{3} \mathrm{NaCl}$ aqueous solution containing $0.001 \mathrm{~mol} / \mathrm{dm}^{3} \mathrm{Ba}^{2+}$ ions, the latter samples were matured for 2 weeks.

The small changes of crystal size upon adsorption of divalent ions from the solution of the concentration smaller/equal $0.001 \mathrm{~mol} / \mathrm{dm}^{3}$ prove mechanism of these ions adsorption through the ion exchange and adsorption on the hydroxyl group of the HAp surface.

The comparison of specific surface area and porosity of the initial hydroxyapatite sample and those conditioned for 2 weeks in the $0.001 \mathrm{~mol} / \mathrm{dm}^{3} \mathrm{NaCl}$ solution and the $0.001 \mathrm{~mol} / \mathrm{dm}^{3} \mathrm{NaCl}+0.001 \mathrm{~mol} / \mathrm{dm}^{3} \mathrm{Ba}^{2+}$ ions mixture. As one can seen the samples conditioned in the aqueous solution of $\mathrm{NaCl}$ and in the $\mathrm{NaCl}$ and $\mathrm{Ba}^{2+}$ mixture exhibit an increase of the specific surface area and an insignificant decrease of average pore diameter, Table 4 . These small effects can be a result of dissolution and precipitation processes occurring in the aqueous solutions which leads to opening new pores. However, the inspection shape of pore size distribution plot, Fig. 10, for these samples exhibit a small decrease of contribution of pores that have the diameter larger than that of the peak of pore size distribution and the small increase contribution of pores with a smaller diameter, Fig. 10. The effect of adsorption on the specific surface area and porosity was different from that observed for the of hydroxyaptite sample with the adsorbed $\mathrm{Sr}^{2+}$ ions (Janusz and Skwarek 2016). This difference may result from

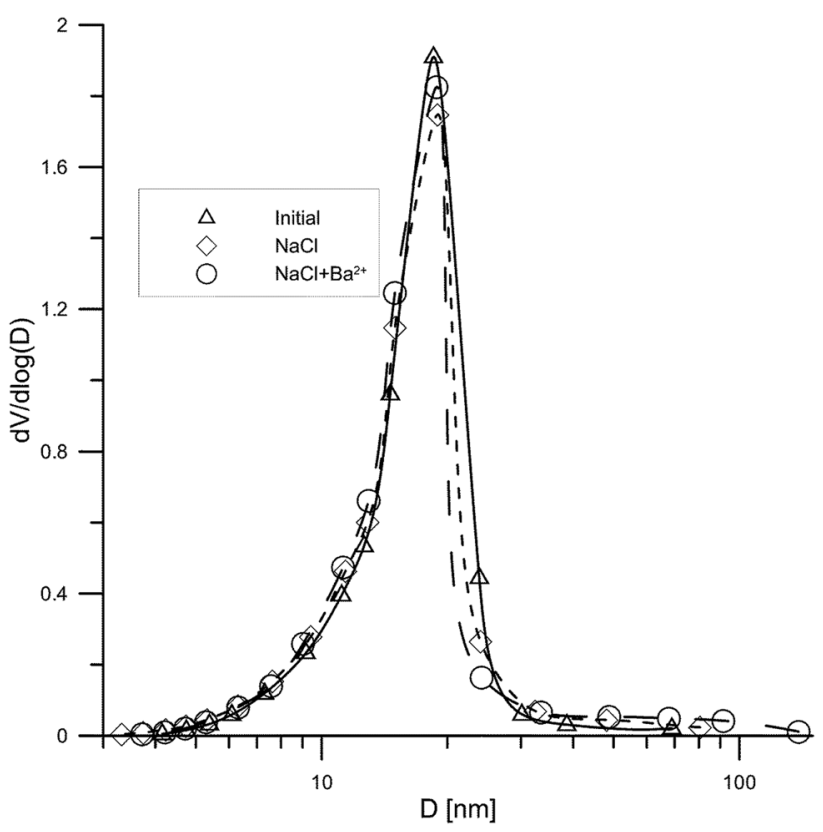

Fig. 10 Pore size diameters of the investigated hydroxyapatite samples

the of size of adsorbed ions because $\mathrm{Sr}^{2+}$ adsorption leads to a significant decrease in the crystal size and changes in aggregation of hydroxyapatite particles.

\subsection{Particle size effect of $\mathrm{Ba}^{2+}$ ions adsorption on hydroxyapatite}

The precipitation and dissolution processes during adsorption of divalent ions in the hydroxyapatite/aqueous 


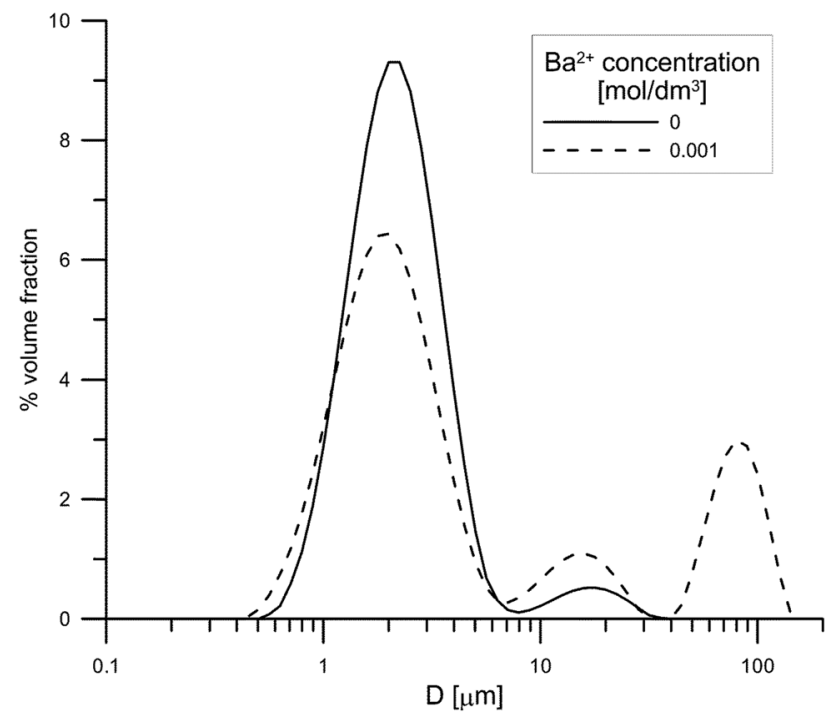

Fig. 11 The comparison of particle size distribution of hydroxyapatite matured in $0.001 \mathrm{~mol} / \mathrm{dm}^{3} \mathrm{NaCl}$ in the absence and presence of $\mathrm{Ba}^{2+}$ ions

electrolyte solution system can result in appearance of small particles due to dissolution of primordial hydroxyapatite particles as well as nucleation of a new phase. The effects of $\mathrm{Ba}^{2+}$ ions adsorption for 7 days on the particle size distribution of hydroxyapatite are given in Fig. 11. For comparison the particle size distribution of the hydroxyapatite sample matured for 7 days in the $0.001 \mathrm{~mol} / \mathrm{dm}^{3} \mathrm{NaCl}$ solution is presented. As can be seen maturation of HAp in the solution containing $\mathrm{Ba}^{2+}$ ions causes trimodal distribution of particles. The decrease of the fraction of fine particles in the range $0.5-7 \mu \mathrm{m}$ and the increase of particles fraction in the range 7-30 $\mu \mathrm{m}$ were observed and additionally, a new fraction of particles, size from 40 to $150 \mu \mathrm{m}$ appeared. This effect is a result of particle aggregation due to the decrease of absolute zeta potential values in the presence of $\mathrm{Ba}^{2+}$ ions, Fig. 8.

\section{Conclusions}

The course of adsorption kinetics indicates that at the beginning adsorption proceeds quickly and then slowly. The results of measurements of $\mathrm{Ba}^{2+}$ ions adsorption kinetics on hydroxyapatite were adjusted fit to the pseudo-first order equation or by means of the pseudo-second order equation, particle intraparticle diffusion model and multiexponential equation and the multiexponential equation was chosen as the best were chosen for the kinetic adsorption. Desorption of $\mathrm{Ba}^{2+}$ ions from hydroxyapatite due to $\mathrm{pH}$ decrease was $18 \%$ in the case of desorption from the solution of the initial concentration $0.00001 \mathrm{~mol} / \mathrm{dm}^{3} \mathrm{Ba}^{2+}$ and $41 \%$ from the solution of the initial concentration $0.001 \mathrm{~mol} / \mathrm{dm}^{3} \mathrm{Ba}^{2+}$.

The adsorption of $\mathrm{Ba}^{2+}$ ions increases with the increase of $\mathrm{pH}$ of solution which may indicate the contribution of $\mathrm{Ba}^{2+}$ ions reaction with surface hydroxyl or hydrophosphate groups. The comparison of the amount of $\mathrm{Ba}^{2+}$ ins adsorption with release of $\mathrm{H}^{+}$as a result of this process indicates that at $\mathrm{pH} 755 \% \mathrm{Ba}^{2+}$ ions are adsorbed on the surface groups and the other adsorbed $\mathrm{Ba}^{2+}$ ions via exchange with the crystal lattice calcium ions.

The sorption isotherm shape indicates that for the initial concentration of $\mathrm{Ba}^{2+}$ ions larger than $0.001 \mathrm{~mol} / \mathrm{dm}^{3}$ dissolution of hydroxyapatite and precipitation of new barium phosphate can take place.

Adsorption of $\mathrm{Ba}^{2+}$ ions decreases the absolute value of the zeta potential and due to decreasing electrostatic repulsion forces between the hydroxyapatite particles leads to significant aggregation hydroxyapatite particles.

The adsorption process has a small effect on the crystal lattice parameters and crystallinity degree. The maturation of hydroxyapatite in the $0.001 \mathrm{~mol} / \mathrm{dm}^{3}$ solution of $\mathrm{NaCl}$ or the mixture of $0.001 \mathrm{~mol} / \mathrm{dm}^{3} \mathrm{NaCl}$ and $0,001 \mathrm{~mol} / \mathrm{dm}^{3}$ $\mathrm{Ba}^{2+}$ ions for 2 weeks causes an increase of the specific area of hydroxyaptite samples and small changes of samples porosity.

OpenAccess This article is distributed under the terms of the Creative Commons Attribution 4.0 International License (http://creativeco mmons.org/licenses/by/4.0/), which permits unrestricted use, distribution, and reproduction in any medium, provided you give appropriate credit to the original author(s) and the source, provide a link to the Creative Commons license, and indicate if changes were made.

\section{References}

Bertinetti, A., Tampieri, E., Landi, C., Ducati, P., Midgley, A., Coluccia, S., Martra, G.: Surface structure, hydration, and cationic sites of nanohydroxyapatite: UHR-TEM, IR, and microgravimetric studies. J. Phys. Chem. C 111, 4027-4035 (2007)

Boanini, E., Gazzano, M., Bigi, A.: Ionic substitutions in calcium phosphates synthesized at low temperature. Acta Biomater. 6, 1882-1894 (2010)

Ferrari, M., Lutterotti, L.: Method for the simultaneous determination of anisotropic residual stresses and texture by X-ray diffraction. J. Appl. Phys. 76(11), 7246-7255 (1994)

Fihri, A., Len, C., Varma, R.S., Solhy, A.: Hydroxyapatite: a review of syntheses, structure and applications in heterogeneous catalysis. Coord. Chem. Rev. 347, 48-76 (2017)

Fischer, A., Malara, P., Wiechuła, D.: The study of barium concentration in deciduous teeth, impacted teeth, and facial bones of polish residents. Biol Trace Elem Res. 161, 32-37 (2014)

Haider, A.S.,.Haider, S., Han, S., Kang, I.K.: Recent advances in the synthesis, functionalization and biomedical applications of hydroxyapatite: a review. RSC Adv. 7, 7442-7458 (2017)

Hashimoto, Y., Sato, T.: Removal of aqueous lead by poorly-crystalline hydroxyapatites. Chemosphere 69, 1775-1782 (2007) 
Hayes, K.F., Katz, L.E.: Application of X-ray Adsorption Spectroscopy for Surface Complexation Modeling of Metal Ion Sorption. in Physics and Chemistry of Mineral Surfaces. Brady, P.V. (ed.), CRC Press, Boca Raton (2000), Chap. 3

Janusz, W., Skwarek, E.: Study of sorption processes of strontium on the synthetic hydroxyapatite. Adsorption 22, 697-706 (2016)

Kukura, M., Bell, L.C., Posner, A.M., Quirk, J.P.: Radioisotope determination of the surface concentration of calcium and phosphorous on hydroxyapatite in aqueous solution. J. Phys. Chem. 76, 900-904 (1972)

Landi, E., Tampieri, A., Celotti, G., Sprio, S.: Densification behavior and mechanisms of synthetic hydroxyapatites. J. Eur. Ceram. Soc. 20, 2377-2387 (2000)

Li, Y., Wang, D., Lim, S.: Fabrication and applications of metal-iondoped hydroxyapatite nanoparticles. JOJ Mater. Sci. 1(2): https:// doi.org/10.19080/JOJMS.2017.01.555559 (2017)

Marczewski., A.W.: Kinetics and equilibrium of adsorption of organic solutes on mesoporous carbons. Appl. Surf. Sci. 253, 5818-5826 (2007)

Monteil Riveira, F., Fedoroff, M.: Sorption of inorganic species on apatite's from aqueous solutions. In: Encyclopedia of Surface and Colloid Science. New York, Marcel Dekker Inc. (2004)

Moussa, S.B., Lachheb, J., Gruselle, M., Maaten, B., Kriis, K., Kanger, T.,. Tonsuaadu, K.,. Badraoui, B.: Calcium, barium and strontium apatites: a new generation of catalysts in the biginelli reaction. Tetrahedron. 73, 6542-6548 (2017)

Pan, X., Wang, J., Zhang, D.: Sorption of cobalt to bone char: Kinetics, competitive sorption and mechanism. Desalination 249, 609-614 (2009)

Reichert, J., Binner, J.G.P.: J. Mat. Sci. 31, 1231-1241 (1996)

Saleb, P.Z., de Bruyn, P.L.: Surface properties of alkaline earth apatites. J. Electroanal. Chem. 37, 99-118 (1972)

Sheha, R.R.: Sorption behavior of $\mathrm{Zn}(\mathrm{II})$ ions on synthesized hydroxyapatites. J. Colloid Interface Sci. 310, 18-26 (2007)

Skwarek, E., Janusz, W.: Adsorption of Cd(II) ions at the hydroxyapatite/ electrolyte solution interface. Sep. Sci. Technol. 51, 11-21 (2016)

Smiciklas, I., Dimovic, S., Plecas, I., Mitric, M.: Removal of $\mathrm{Co}^{2+}$ from aqueous solutions by hydroxyapatite. Water Res. 40, 2267-2274 (2006)
Smiciklas, I., Onjia, A., Raicevic, S., Janackovic, D., Mitric, M.: Factors influencing the removal of divalent cations by hydroxyapatite. J. Hazard. Mater. 152, 876-884 (2008)

Smicklas, I.D.: Cadmium immobilization by hydroxyapatite. Chem. Ind. 57, 101-106 (2003)

Stumm, W.: Chemistry of the Solid-Water Interface. Wiley, New York (1992)

Sudarsanan, K., Young, R.A.: Significant precision in crystal structural details. Holly Springs hydroxyapatite. Acta Crystallogr. Sect. B 25, 1534-1535 (1969)

Sugiyama, S., Moffat, J.B.: Cation conversion of mehtanol on calcium, strontium, barium and lead hydroxyapatites. Catal. Lett. 81, 77-81 (2002)

Sugiyama, S., Fukuda, N., Matsumoto, H., Hayashi, H., Shigemoto, N., Hiraga, Y., Moffat, J.B.: Interdependence of anion and cation exchanges in calcium hydroxyapatite: $\mathrm{Pb}^{2+}$ and $\mathrm{Cl}^{-}$. J. Colloid Interface Sci. 220, 324-328 (1999)

Suzuki, T., Hatsushika, T., Hayakawa, Y.: Synthetic hydroxyapatites employed as inorganic cation-exchangers. Part 1. J. Chem. Soc., Faraday Trans I 77, 1059-1069 (1981)

Suzuki, T., Hatsushika, T., Hayakawa, Y.: Synthetic hydroxyapatites as inorganic cation exchangers, Part 2. J. Chem. Soc., Faraday Trans I 77, 3605-3611 (1982)

Wakamura, M., Kandori, K., Ishikawa, T.: Surface composition of calcium hydroxyapatite modified with metal ions. Colloids Surf. A: Physicochem. Eng. Asp. 142, 107-116 (1998)

$\mathrm{Xu}$, Y., Schwartz, F.W., Traina, S.J.: Sorption of $\mathrm{Zn}^{2+}$ and $\mathrm{Cd}^{2+}$ on hydroxyapatite surfaces. Environ. Sci. Technol. 28, 1472-1480 (1994)

Yasukawa, A., Nakajima, M., Kandori, K., Ishikawa, T.: Preparation and characterization of carbonated barium hydroxyapatites. J. Colloid Interface Sci. 212, 220-227 (1999)

Yodera, C.H., Pasteris, J.D., Krol, K.A., Weidner, V.L., Schaeffer, R.W.: Synthesis, structure, and solubility of carbonated barium chlor- and hydroxylapatites. Polyhedron 44, 143-149 (2012)

Zilm, M.E., Chen, L., Sharma, V., Mc Dannald, A., Jain, M., Ramprasada, R., Wei, M.: Hydroxyapatite substituted by transition metals: experiment and theory. Phys. Chem. Chem. Phys. 18, 16457-16465 (2016) 